\title{
Extrusão de placa escleral senil: relato de um caso
}

\author{
Extrusion of a senile scleral plaque: A case report
}

\author{
Eduardo Ferrari Marback ${ }^{(1)}$ \\ Renato Luiz Gonzaga ${ }^{(2)}$ \\ Márcia Serva Lowen ${ }^{(3)}$ \\ Moacir Pezati Rigueiro ${ }^{(4)}$ \\ Clélia Maria Erwenne ${ }^{(5)}$
}

\begin{tabular}{|c|}
\hline RESUMO \\
\hline Objetivo: Relatar caso de extrusão parcial espontânea de placa de \\
transluscência focal senil de esclera calcificada. \\
Método: Relato de caso de mulher de 75 anos, encaminhada com \\
suspeita de tumor conjuntival, apresentando lesão leucoplásica em \\
esclera, localizada anteriormente à inserção do músculo reto medial \\
do olho esquerdo causando sensação de corpo estranho; instituindo- \\
se tratamento por exérese e enxerto escleral. O exame histopatológico \\
revelou tecido conjuntivo fibroso com calcificação. \\
Conclusão: A extrusão de placa de transluscência senil de esclera \\
deve ser considerada no diagnóstico diferencial dos tumores epibul- \\
bares.
\end{tabular}

Palavras-chave: Transluscência focal senil de esclera; Tumores epibulbares.
Trabalho realizado pelo Setor de Tumores do Departamento de Oftalmologia da Escola Paulista de Medicina, Universidade Federal de são Paulo em conjunto com o Departamento de Patologia da Escola Paulista de Medicina, Universidade Federal de São Paulo.

(1) Pós Graduando, Departamento de Oftalmologia, Escola Paulista de Medicina, Universidade Federal de São Paulo.

(2) Mestre em Oftalmologia pela Universidade Federal de São Paulo, médico colaborador dos Setores de Tumores Oculares do Departamento de Oftalmologia da Escola Paulista de Medicina, Universidade Federa de São Paulo e Hospital A.C. Camargo, Fundação Antônio Prudente.

(3) Médica do Departamento de Patologia da Escola Paulista de Medicina, Universidade Federal de São Paulo.

(4) Professor Adjunto do Departamento de Patologia da Escola Paulista de Medicina, Universidade Federal de São Paulo.

(5) Doutor em Oftalmologia pela Escola Paulista de Medicina, Universidade Federal de São Paulo. Chefe dos Setores de Tumores Oculares do Departamento de Oftalmologia da Escola Paulista de Medicina, Universidade Federal de São Paulo e Hospital A.C. Camargo, Fundação Antônio Prudente. Membro do Grupo de Braquiterapia Ocular do Hospital Israelita Albert Einstein.

Endereço para correspondência: Av. Dr. Altino Arantes, 835, apt ${ }^{\circ} 104$, Vila Clementino. São Paulo (SP) CEP 04042-034. Tel.: (11) 5581-2144. E-mail: marback@sol.com.br

\section{INTRODUÇÃ̃O}

Transluscência focal senil da esclera é um achado clínico relativamente comum em pacientes idosos ${ }^{1,2}$. Tais lesões são caracterizadas por um aumento da transparência escleral, com diminuição da celularidade e visualização por transparência de pigmento uveal, classicamente localizadas anteriormente à inserção dos músculos retos horizontais ${ }^{1,2}$. O estudo histopatológico mostra que não há afinamento escleral associado, e eventualmente há até um certo aumento localizado de espessura ${ }^{1,3}, 0$ colágeno não se encontra hialinizado, mantendo sua estrutura fibrilar normal ${ }^{1,4}$; presença de calcificação é freqüente ${ }^{1}$ e a extrusão de placas esclerais é achado bastante raro. O objetivo desse estudo é relatar um caso de placa escleral senil calcificada, em processo de expulsão, tratado cirurgicamente.

\section{APRESENTAÇÃO DO CASO}

Paciente de 75 anos, feminina, encaminhada ao Setor de Tumores do Departamento de Oftalmologia da Universidade Federal de São Paulo com história de lesão tumoral em olho esquerdo (OE) há 8 meses, causando vermelhidão ocular localizada e sensação de corpo estranho. Negava patologias sistêmicas associadas. De antecedentes oculares, havia sido submetida a cirurgia de catarata em OE há 10 anos, sem bom resultado visual.

Ao exame apresentava acuidade visual sem correção de visão de vultos em olho direito (OD) e conta dedos a 2 metros em OE. À biomicroscopia observou-se em OE lesão placóide localizada anteriormente à inserção do reto medial, de coloração esbranquiçada, aparen- 
temente com origem intra- escleral, com metade temporal elevada, causando erosão da conjuntiva nessa região (Fig. 1). Os vasos conjuntivais ao redor da lesão apresentavamse congestos. Havia ainda opacidade total de cristalino em OD e afacia no OE. Pressão intra-ocular em ambos os olhos, e fundoscopia à esquerda normais. A biomicroscopia ultra-sônica revelou imagem sugestiva de calcificação na lesão que impedia avaliação da profundidade da mesma, bem como a espessura do leito escleral subjacente.

A paciente foi submetida a exérese da lesão escleral sob anestesia local e, como a esclera remanescente apresentava-se delgada, foi feito um enxerto usando esclera de cadáver preservada, com sutura em pontos simples de poligalactina 6-0. A paciente evoluiu com resolução da sintomatologia e bom aspecto da região no pós-operatório tardio.

$\mathrm{O}$ estudo histopatológico do material ressecado revelou presença de tecido conjuntivo fibroso denso, com extensa área central de calcificação (Fig.2).

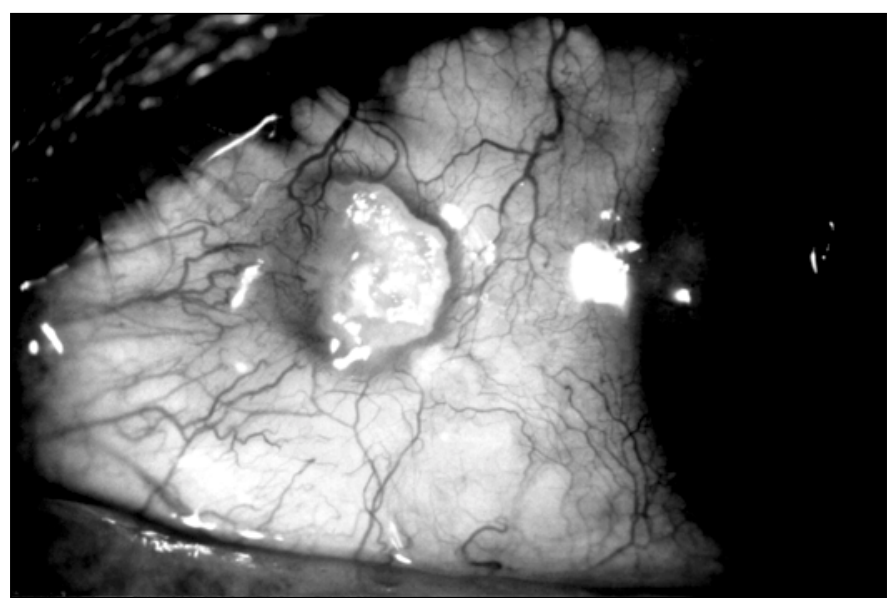

Fig. 1- Lesão placóide elevada e esbranquiçada, localizada adiante da inserção do reto medial

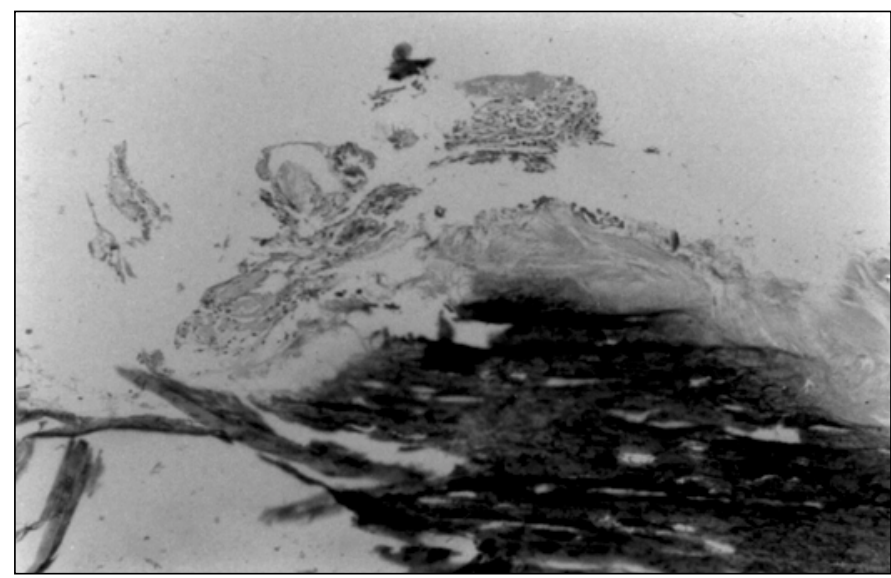

Fig. 2- Secção histológica corada pela hematoxilina - eosina, revelou tecido conjuntivo denso com ampla área de calcificação.

\section{DISCUSSÃO}

Embora relativamente freqüente como achado de exame, a fisiopatologia da transluscência focal senil da esclera ainda não está estabelecida. O estresse causado pela tração muscular, isquemia, ressecamento e lesão actínica crônica já foram aventados como possíveis etiologias, porém sem argumentos conclusivos ${ }^{3}$. O achado de expulsão de placa de transluscência focal senil de esclera calcificada é evento raro, sendo denominado por Manschot como "escleromalácia senil” em $1978^{4}$. Tal lesão difere da escleromalácia perfurante por acometer pacientes em idade avançada, não estar associada a patologia reumática, ter localização característica, associar-se eventualmente à presença de transluscência focal senil da esclera no olho contralateral, ausência de reação inflamatória exuberante nos tecidos adjacentes, e por apresentar leito escleral remanescente sob a placa calcificada ${ }^{3}$. Apesar do grande afinamento escleral, não parece haver tendência à perfuração ocular espontânea ${ }^{1,4}$. A despeito disso, no caso ora relatado, achamos mais seguro realizar enxerto escleral na área subjacente, face ao seu adelgaçamento.

Histologicamente a transluscência focal senil da esclera é vista como uma zona de maior basofilia do colágeno e menor celularidade da esclera que leva à descoloração e aumento de transparência ${ }^{1-3}$. A espessura escleral nessas áreas é dita como normal ou aumentada, exceto quando há calcificação, que acontece na parte intermediária da esclera, deixando um leito remanescente com $1 / 3$ a $1 / 6$ da espessura original ${ }^{1,3}$. Nesses casos o cálcio encontrado nas placas está sob a forma de seus sais de carbonato ou fosfato ${ }^{3}$.

No caso em pauta optou-se pelo procedimento cirúrgico por haver sintomatologia correlata. Em casos assintomáticos este procedimento não deve ser adotado, já que não há risco comprovado de perfuração ocular espontânea. Em nossa paciente, o achado de lesão de parede elevada causado pelo processo de extrusão, levou o oftalmologista que forneceu o atendimento primário a suspeitar de tumoração, encaminhado a paciente para setor de referência terciária. Diante de tal situação, convém incluir esta patologia na lista de diagnóstico diferencial dos tumores da superfície ocular.

\section{SUMMARY}

Purpose: To present a case of spontaneous extrusion of a calcified plaque of scleral focal senile translucency.

Methods: Case report of a 75-year-old female, referred because of a epibulbar tumor suspicion. She complained of foreign body sensation and had a white scleral plaque in front of the left medial rectus insertion. The lesion was exci-sed and a scleral graft performed. The histologic 
examination showed fibrous connective tissue, with calcification.

Conclusion: Spontaneous extrusion of senile scleral plaques should be included in the differential diagnosis of epibulbar tumors.

Keywords: Scleral focal senile translucency; Epibulbar tumors.

\section{REFERÊNCIAS BIBLIOGRÁFICAS}

1. Marback RL. Placa Escleral (translucência focal senil da esclera). Arq Bras Oftal 1974;34:130-3

2. Spencer WH. Sclera, in Spencer WH (ed): Ophthalmic Pathology An Atlas and Textbook. Philadelphia, PA, WB Saunders Company, 1996;334-71.

3. Scroggs MW, Klintworth GK. Senile Scleral Plaques: A Histopathologic Study Using Energy-Dispersive X-ray Microanalysis. Hum Pathol1991;22:557-62.

4. Manschot WA. Senile scleral plaques and senile scleromalacia. Br J Ophthalmol 1978;62:376-80.

\title{
I CONGRESSO PAN-AMERICANO DE TRAUMA OCULAR
}

\author{
22 a 24 de Março de 2001 \\ GRANDVILLE HOTEL \\ Belo Horizonte-MG
}

Promoção: Sociedade Pan-Americana de Trauma Ocular

Presidente: Dr. Christiano Barsante

Informações: Consult Comunicação e Marketing

Tel./Fax: (31) 274-1550

e-mail:_comunica@consultcom.com.br

internet: www.consultcom.com.br 